\title{
FREQUÊNCIA DE AGLUTININAS ANTI-LEPTOSPIRA EM EQUÍDEOS ABATIDOS EM FRIGORÍFICO EXPORTADOR DO ESTADO DE MINAS GERAIS
}

\author{
FREQUENCY OF ANTI- LEPTOSPIRA AGGLUTININS IN EQUIDS SLAUGHTERED \\ IN MINAS GERAIS STATE
}

\author{
M. E. C. FURQUIM ${ }^{1}$, R. F. SANTOS ${ }^{2}$, L. A. MATHIAS ${ }^{3}$
}

\begin{abstract}
RESUMO
A leptospirose é uma zoonose de distribuição mundial causada por bactérias do gênero Leptospira spp. Nos equídeos, a não eliminação deste microrganismo dos túbulos renais após a resolução da bacteremia torna tal espécie uma importante fonte de infecção na cadeia epidemiológica da doença. Desta forma, este estudo avaliou a frequência de aglutininas anti-Leptospira em amostras de soro de equídeos abatidos em frigorífico exportador. Foram coletadas 107 amostras de soro equídeo durante o abate. Dessas, 73 eram provenientes de equídeos machos e 34 de fêmeas. Esses animais, sem raça definida, eram provenientes dos estados de Minas Gerais, São Paulo, Goiás, Bahia e Mato Grosso do Sul. A Soroaglutinação Microscópica (SAM) foi empregada como método diagnóstico e foram utilizadas 24 sorovariedades de Leptospira spp. Uma proporção de $92,52 \%$ dos animais foi reagente a uma ou mais sorovariedades na SAM, com títulos iguais ou superiores a 100. As sorovariedades de maior ocorrência foram Icterohemorrhagiae (71,96\%), Cynopteri (38,22\%), Grippotyphosa $(29,91 \%)$ e Pyrogenes (26,17\%). Observou-se que $100 \%$ dos municípios possuíam animais soropositivos a uma ou mais sorovariedades de Leptospira spp. A partir dos resultados obtidos pode-se confirmar a importância dos equídeos na cadeia epidemiológica da leptospirose, uma vez que a eliminação deste microrganismo através da urina ocorre por muitas semanas após a infecção. Tais resultados também demonstram que estes equídeos foram altamente expostos a diversas sorovariedades de Leptospira spp. Desta forma, a leptospirose equina não deve ser negligenciada, a fim de assegurar a saúde pública e a saúde animal, bem como reduzir os riscos ocupacionais.
\end{abstract}

PALAVRAS-CHAVE: LEPTOSPIROSE. EQUINOS. DIAGNÓSTICO SOROLÓGICO.

ÁREA TEMÁTICA: Epidemiologia

\footnotetext{
${ }^{1}$ Mestranda do Programa de Pós-Graduação em Medicina Veterinária (Medicina Veterinária Preventiva) - Faculdade de Ciências Agrárias e Veterinária (Unesp). Câmpus Jaboticabal - SP.

*mecfurquim@yahoo.com.br

${ }^{2}$ Doutoranda do Programa de Pós-Graduação em Medicina Veterinária (Medicina Veterinária Preventiva) Faculdade de Ciências Agrárias e Veterinária (Unesp). Câmpus Jaboticabal - SP

${ }^{3}$ Professor Titular do Departamento de Medicina Veterinária Preventiva e Reprodução Animal - Faculdade de Ciências Agrárias e Veterinária (Unesp). Câmpus Jaboticabal - SP
} 